\title{
Simulation-Based Optimization of the Sea Trial on Ships
}

\author{
Yusuf GENÇ ${ }^{1}$, Murat ÖZKÖK² \\ ${ }^{1}$ Ordu University, Fatsa Vocational Higher School, Turkey \\ ${ }^{2}$ Karadeniz Technical University, Surmene Faculty of Marine Sciences, Turkey \\ yusufgenc@odu.edu.tr; ORCID ID: https://orcid.org/0000-0002-4903-5015 \\ muratozkok@ktu.edu.tr; ORCID ID: https://orcid.org/0000-0002-1782-8694 \\ Corresponding Author: Yusuf GENÇ
}

\begin{abstract}
As well known, ships which have complex production processes are subject to various tests made on every stage in many fields from the beginning to the end of the production. After the tests are completed successfully, the ship is delivered to the ship-owner. "Sea trial" being the last stage of these tests, is examined in detail in this study. The purpose of this study is to plan the tests performed in the sea trial by the means of computer programs and to suggest shorter completion period for the tests. Thus, reducing the total cost of the cruising. Moreover, shortening the duration of the cruise will be a factor that can speed up the delivery of the ship. For this purpose, the tests and processes performed during the sea trial are listed. A cruise process flow diagram including all the tests applied under normal conditions was created, and the data were entered into the SIMIO simulation program. As a result, it was determined that the total cruising time was 28,0989 hours. After that, a new flow diagram was created by making some improvements in the current testing process, and a new simulation model was built up. In the new simulation model, total time spent to complete the tests were 25,3567 hours, so the testing time was shortened by $2.75(9,76 \%)$ hours.
\end{abstract}

\section{Keywords}

Sea Trial, Shipbuilding, SIMIO, Simulation, Optimization.

\section{Introduction}

Ships are marine vehicles that are manufactured at very high costs in shipyards and have complex production processes. A shipyard must manage the complex processes successfully and deliver the ship to the ship-owner on time. During the construction phase of a ship in the shipyard, many variables consisting of different main topics, such as the correct placement of production lines, the selection of the right equipment, the qualifications of the workers, the experience of the engineering staff, and the selection of an appropriate subcontractors, directly affect the performance and the efficiency of the shipyard, and therefore the punctuality of the delivery. The shipbuilding contracts must be made consciously and freely by the parties, as in every contract [1]. Since 
the delivery time of the ship depends on the agreement between the shipowner and the shipyard, there will be financial losses on both parties in the event of any delays on the delivery dates. Moreover, delay of the ship's delivery due to shipyard may cause negative business consequences for the future of the shipyard.

Given the quality standards and delivery times of the manufactured ships, the general situation of shipyards has paramount importance. With the rapid developments in computer technology and the successful use of these developments in ship engineering, computer simulation methods based on mathematical models have become effective [2]. Depending on the progress of these methods, it is also possible to shorten the delivery times of the ship because ship production considerably varies technologically. Thus, the use of simulation programs in the shipyards allows us to foresee the possible problems, do planning in different scenarios for production and tests.

Ship production is a process that must be continuously monitored and supervised from the beginning of the project phase. In this process, beginning with the tests done on the equipment manufactured in factories, various tests must be carried out within certain rules during each production phase in the shipyards. These tests need to be passed incrementally. It is necessary to check if the ship formed through various stages during the construction period meets the necessary requirements in several points such as safety, maneuverability, equipment, and sufficiency. For this purpose, however, experiences differ throughout the cruise. The International Maritime Organization (IMO) states that it is imperative to perform rotational, zigzag, and stop maneuvers to determine if 100-meter large ships have sufficient maneuverability [3]. Since these tests and experiments conducted in the shipyards are carried out under the supervision of the ship representatives and the class, they assist future crew members of the ship to get familiarised.

\section{Literature Research}

Thanks to today's technology, simulation programs are used in every field of the industry to see the possible problems that may emerge in the system or working order and to move the production to better levels. Simulation is widely used, especially in the areas where production is continuous and automation-related, such as transportation, medical services, and supply chain.

Ponsignon and Mönch [4] studied factories that had complex manufacturing. By creating production planning based on simulation, they evaluated them with a scenario. It was found out that the simulation could produce stable plans. Medeiros et al. [5] developed models of plate processing operations in terms of the modernization of the plate production line by making simulation-based work on ship-building yard manufacturing process. Caprace et al. [6] developed a simulation on manufacturing processes such as block erection in the shipyard using optimization techniques. It was observed that the choice of a correct mounting sequence had a positive contribution on the production lead time. Another simulation study was carried out by Roh and Lee [7]. In this study, using the 3D CAD method, a suitable simulation method was developed for block mounting for the whole-body structure of the ship. By using the 3D CAM model, the block division method was created, and it was seen that the block mounting was simulated appropriately in the initial design phase. Yuguang [8] proposed the Petri network to make a good block assembly model in shipbuilding industry. He showed that he could contribute to normal planning processes by developing algorithms during assembly with the Petri net model he used. Lamb et al. [9] investigated the validity 
of theoretical approaches and models using international competitive shipyard production data in their work to improve the shipbuilding process. They defined the shipbuilding process as a result of long studies and modellings. In their work, Cheng and Hongxiang [10] concluded that by simulating the anchorage operation of the ship with the help of Visual C ++, the results obtained can help the staff working on the deck as an exercise.

Abdel-atif et al. [2], by using Simulink software, made use of hydrodynamic forces and moments based on modular mathematics to simulate the maneuver behavior of the Esso Osaka tanker class ship. They also tested the rotation and zigzag motion and achieved successful results. Cha et al. [11] applied the simulation study that they proposed in the ship and offshore structures to the block assembly process in their study. As a result, they concluded that the simulation work would be useful in this framework, and the development area could be provided. Nam et al. [12] have emphasized the importance of using the simulation at the shipyard in their study. They also tried to create a common structure that would facilitate simulation at shipyards, claiming that it would be a customized simulation for each shipyard. Cha et al. [13], in another study, simulated the block assembly process, which was carried out with a floating crane, by taking the 6 degrees of freedom movements into consideration. Thus, it can be deduced that the resonance frequency can be predicted by simulation, and the situation that may cause danger can be detected in the early stage. Shin and Sohn [14] developed an automated production system for product flow control at a workplace by using objective information technologies such as modeling and networking, emphasizing the importance of the automated shipbuilding process. In this way, product flow simulation was carried out and the problems on the process were evaluated. Ljubenkov et al. [15], have emphasized the importance of using simulation in the shipbuilding production process in their work. It has been seen that the shipbuilding with a complicated production process can be identified with the simulation method, and the parts which may create bottlenecks and problems can be determined. Kim et al. [16] analyzed the simulation of the manufacturing systems in the shipyard in their study. By designing the block erection simulation, they produced a model. Lee et al. [17] dwelled on the panel ship, which was an important part of the shipbuilding production process in their study. The simulation model was verified using a real manufacturing scenario, and the relationship between the model and the panel line was accepted. Hadjina [18] conducted a simulation-based study on the profile cutting line for the shipbuilding process. Vik et al. [19] aimed to get the best production line by using different scenarios in the design phase of a cement plant with SIMIO program. Mandalaki and Manesis [20] made 3D simulations of vessels, vehicles, and human activities for the Patras city port they created in three dimensions with the help of the AutoCAD program. The 3D simulation done with SIMIO aims to examine the changes planned in advance and look for ways to work more effectively in the port with different scenarios. Özkök [21] studied with SIMIO program in his study, and he made the simulation model by making the process analysis of the profile processing unit in the shipyard, and he applied different scenarios to increase the amount of profile production. He concluded that the improvements that can be made on marking and cutting activities can contribute to increasing the amount of profile production. Jeong et al. [22] developed a process-oriented simulation model to simulate the behavior of shipyard logistics. With this simulation, 
the physical movement of each transaction was analyzed, and a logistic indicator was used for the process. Du et al. [23], in another study, proposed a new simulationbased spatial planning program to avoid the spatial layout problem of the blocks. In this way, visual results for the block layout and process diagram were easily obtained. Lee at al. [24], parallel to new production technologies, worked on a simulation-based shipbuilding planning case. They used a process-oriented simulation technique with the help of a new scheduling system for shipbuilding planning processes. By applying the proposed simulation-based planning system to a real shipbuilding process, it was proven that the quality of production planning could be increased. $\mathrm{Ju}$ et al. [25] investigated the mid-term production planning process in the shipyard in detail. Later, they developed a system that can simulate a new discrete event by applying a backward process-centered simulation to this process. The verification of the system was carried out with the production data of four different ships.

\section{Material and Method}

Simulation technology is used in many production areas. It should be known that in today's world, where the competitive environment is constantly increasing, businesses that aim to survive and achieve continuity in production should improve themselves with the help of simulation and similar techniques. Timely delivery of projects and customer satisfaction are very important for the continuity of the business. In this study, which we think will contribute to the delivery process of the ship, the tests to be carried out during the trial course of a ship whose factory acceptance and harbor acceptance tests have been completed are examined with the help of the SIMIO program, which is based on bottleneck and queue theory, and it is foreseen to reduce the total time spent on the cruise. In this context, the 7-step process shown in Figure 1 has been followed.

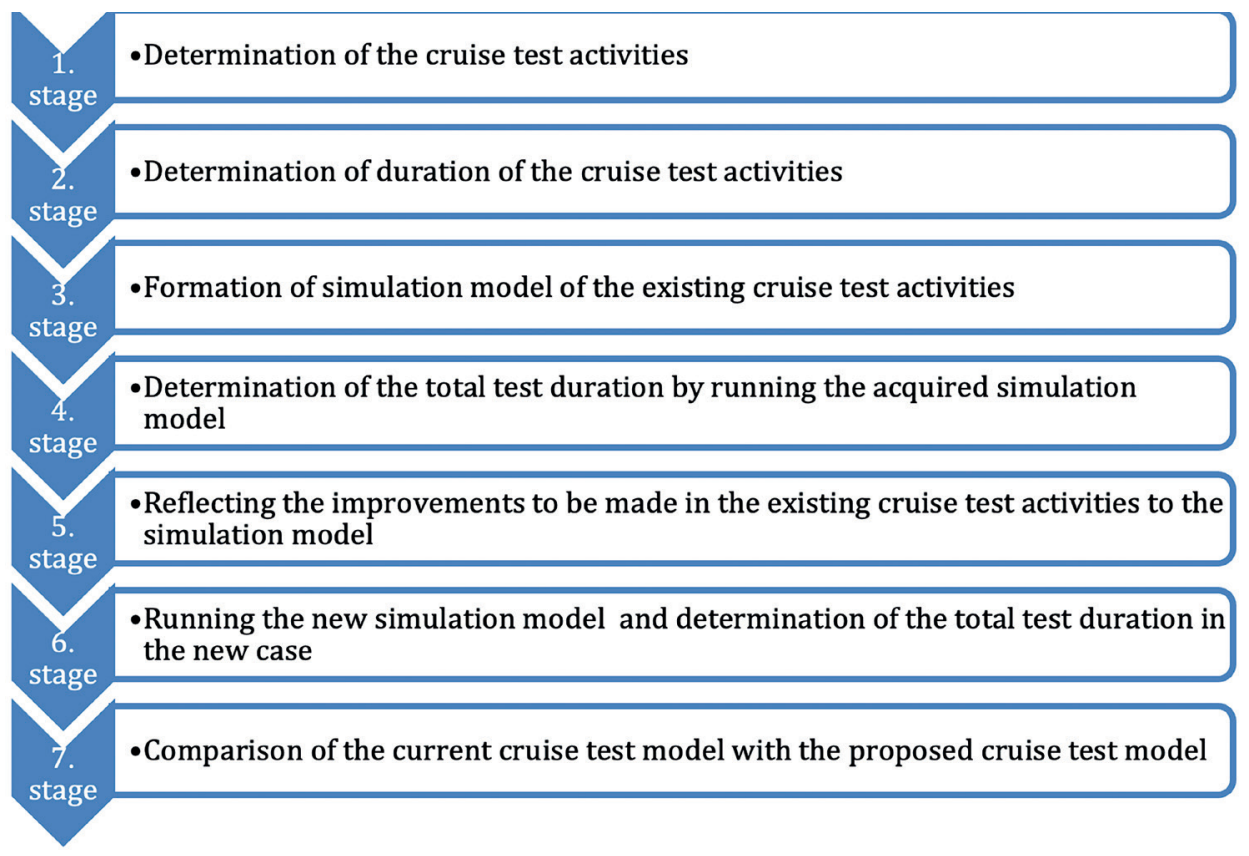

Figure 1. The Process of Obtaining the Simulation Models of the Tests 
- In stage 1 , all the test activities to be carried out on the cruise are identified and listed in a tabular form.

- In stage 2, the durations of the tests to be entered into the SIMIO program are indicated in accordance with the triangular distribution.

- In stage 3, a simulation model of the cruising program, which is available and used in sea trials, has been formed.

- In stage 4, the simulation model has been run, and how long the total duration of the cruise would be under the specified conditions has been stated.

- In stage 5, improvements have been made on the order and sequence of the tests to be done on the cruise, and a new simulation model has been formed.

- In stage 6, a new simulation model has been run, and how long the total duration of the cruise would be in this case has been observed.

- In the 7th stage, the simulation model obtained from the existing cruise test program and the new simulation model obtained after the improvements are compared.

\subsection{Cruise Acceptance Tests and Determination of Duration}

The ship is ready for cruise acceptance tests after the completion of harbor acceptance tests (HAT) and preparations made before the sea trial. For this study, a cruising program of 8400 DWT chemical tanker was used. Tests and controls planned to be made during the sea trial are given in Table 1 . Besides, the application times of the tests and controls corresponds to the data recorded during the sea trial of the 8400 DWT chemical tanker. While preparing Table 1, no order of testing has been applied. Then, using the data in Table 1 , a normal workflow diagram of the sea trial has been composed. Afterwards, in terms of shortening the total spend time in the sea trial, a new diagram is obtained by performing the improvement work on the cruise workflow diagram formed before.

Table 1. Tests and Controls to be Carried Out During the Sea Trial

\begin{tabular}{|c|l|c|c|c|}
\hline \multirow{2}{*}{ Test no } & \multicolumn{1}{|c|}{ "Tests and controls } & \multicolumn{3}{c|}{ Periods (minute) } \\
\cline { 3 - 5 } & & Optimistic & Expected & Pessimistic \\
\hline 1 & $\begin{array}{l}\text { Going abroad of relevant persons } \\
\text { (shipyard, service, class etc.) }\end{array}$ & 45 & 60 & 90 \\
\hline 2 & $\begin{array}{l}\text { Startup meeting (shipyard, ship-owner, } \\
\text { class) }\end{array}$ & 20 & 30 & 45 \\
\hline 3 & $\begin{array}{l}\text { Measurement of ship drafts (fore, stern, } \\
\text { midship) }\end{array}$ & 15 & 20 & 30 \\
\hline 4 & Gyro compass settings & 45 & 60 & 75 \\
\hline 5 & Boiler controls and alarm tests & 30 & 45 & 60 \\
\hline 6 & Bow thruster test - starboard side & 20 & 30 & 40 \\
\hline 7 & Bow thruster test - port side & 20 & 30 & 40 \\
\hline 8 & Transition from MDO to HFo & 15 & 20 & 30 \\
\hline 9 & Booster module tests and its alarms & 20 & 30 & 45 \\
\hline 10 & Separator test and its alarms & 20 & 30 & 45 \\
\hline 11 & Navigation equipment test & 20 & 30 & 45 \\
\hline 12 & Main engine settings & 45 & 60 & 90 \\
\hline
\end{tabular}


Table 1. Tests and Controls to be Carried Out During the Sea Trial (Cont')

\begin{tabular}{|c|c|c|c|c|}
\hline \multirow[t]{2}{*}{ Test no } & \multirow[t]{2}{*}{ Tests and controls } & \multicolumn{3}{|c|}{ Periods (minute) } \\
\hline & & Optimistic & Expected & Pessimistic \\
\hline 13 & Freshwater generator test & 30 & 45 & 60 \\
\hline 14 & Anchor and windlass test starboard side & 20 & 30 & 40 \\
\hline 15 & Anchor and windlass test port side & 20 & 30 & 40 \\
\hline 16 & Double bumps steering test & 10 & 15 & 20 \\
\hline 17 & Single bump steering test & 10 & 15 & 25 \\
\hline 18 & Single bump steering test & 10 & 15 & 25 \\
\hline 19 & Port side turning circle test & 20 & 30 & 45 \\
\hline 20 & Starboard turning circle test & 20 & 30 & 45 \\
\hline 21 & Zig-zag maneuvering test $\left(10^{\circ} / 10^{\circ}\right)$ & 20 & 30 & 45 \\
\hline 22 & Zig-zag maneuvering test $\left(20^{\circ} / 20^{\circ}\right)$ & 20 & 30 & 45 \\
\hline 23 & Speed test & 30 & 45 & 60 \\
\hline 24 & Stopping test & 20 & 30 & 45 \\
\hline 25 & Noise measurement test & 45 & 60 & 90 \\
\hline 26 & Astern trial & 20 & 30 & 45 \\
\hline 27 & Crash stop test & 20 & 30 & 45 \\
\hline 28 & $\begin{array}{l}\text { Automatic slow down alarms/shut down } \\
\text { test }\end{array}$ & 30 & 45 & 60 \\
\hline 29 & Blackout test & 20 & 30 & 45 \\
\hline 30 & Main engine endurance test & 240 & 270 & 300 \\
\hline 31 & Smoke detection test & 45 & 60 & 75 \\
\hline 32 & Automation test (AUT-UMS) & 360 & 400 & 460 \\
\hline 33 & Shaft generator control before AVM-APS & 15 & 20 & 30 \\
\hline 34 & Alternative drive system test (AVM-APS) & 60 & 75 & 90 \\
\hline 35 & $\begin{array}{l}\text { Result meeting (shipyard, ship-owner, } \\
\text { class) }\end{array}$ & 20 & 30 & 45 \\
\hline 36 & Transition from HFO to MDO & 15 & 20 & 30 \\
\hline 37 & Getting back to the shipyard building & 45 & 60 & 90 \\
\hline
\end{tabular}

The following can be stated regarding the sea trial and Table 1:

- While the duration of each test to be performed in the sea trial was being determined, the preparation phase prior to the test was included to the duration.

- Air and sea conditions are suitable for cruising.
- It is assumed that there is no breakdown on the ship from the start to the end of the sea trial.

- In Table 1, the periods of the tests to be entered into the SIMIO program have been determined as appropriate to the triangular distribution. 
3.2. Creating the Simulation Model of the Sea Trial

In Table 1, a sea trial workflow diagram has been created to use in the SIMIO program for the sea trial program, which is composed of 37 items (Figure 2). While this flow diagram was being formed, no improvement work was done on the sea trial program which was performed under normal conditions.
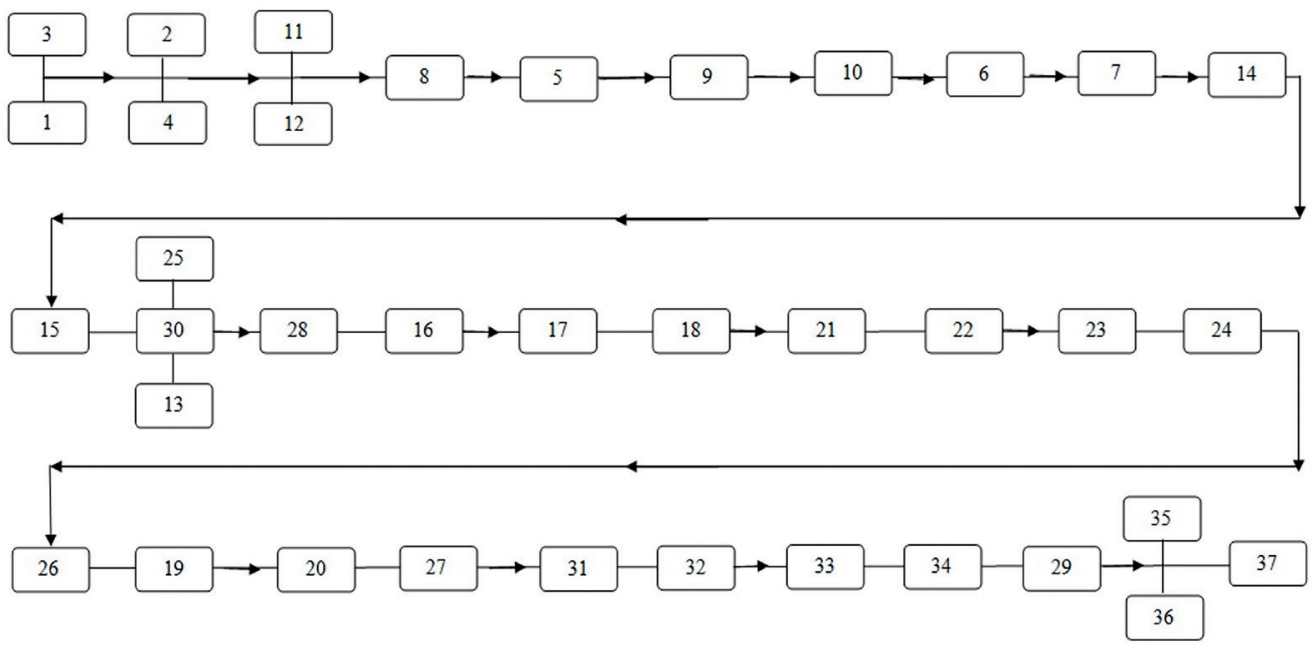

Figure 2. Current Status of the Cruising Program Flow Diagram (Simulation Model)

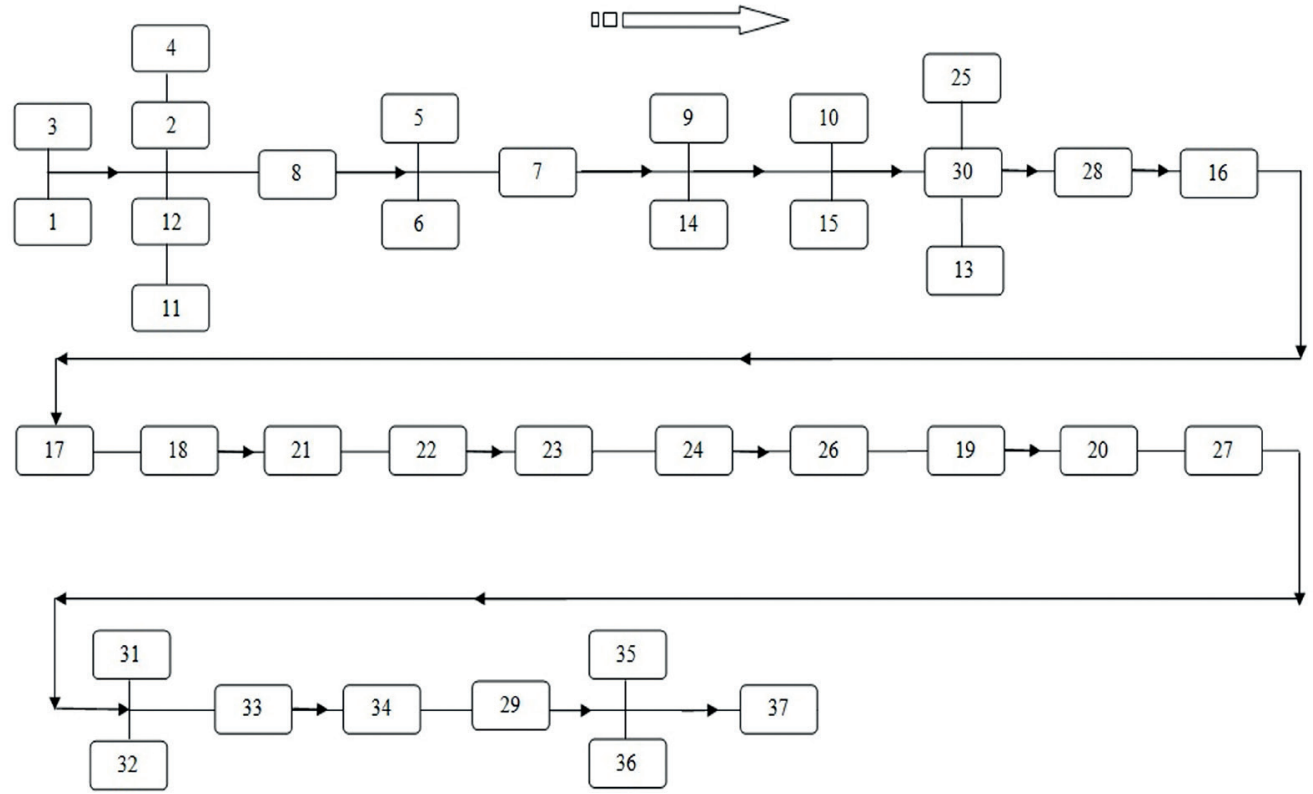

Figure 3. New Status of the Cruising Program Flow Diagram (Simulation Model) 


\subsection{Improvement of the Sea Trial Simulation Model}

In order to conduct the cruising program more efficiently, which is composed of 37 items shown in Table 1 , the test flow created to be used in the SIMIO program has been rearranged to provide better results (Figure 3 ). While preparing this flow diagram, tests that could be done in the same time frame and that will not affect each other were carried out with the help of the experiences gained in the previous sea trial tests. Hence, a certain sequence was followed during the tests, taking factors, such as the position and the speed of the ship, and the difficulty of the test into consideration.

The intended purpose here is to finish the sea trial as soon as possible. Entering the test flow diagram created under these conditions into the SIMIO simulation program, the results were examined, and by comparing the two models, the differences during the sea trial have been observed.

\section{Results and Discussions}

4.1. Current Status of the Sea Trial Simulation Model

Figure 4 shows a 3D image of the simulation model entered the SIMIO program for the current situation. The tests and controls shown in Table 1 have been entered to the program as activities 1,2 , etc. with the sequence numbers specified in accordance with the current state simulation model (Figure 2).

After creating the cruising program simulation model in the program under normal conditions, the program has been run to find out how long the tests will be completed, and the total cruising duration has been observed as 28,0989 hours (Table 2).

\subsection{After the Improvement of the Sea Trial Simulation Model}

Following the findings obtained for the current situation, a new simulation model program has been entered into the program by making a series of improvements. Figure 5 shows the 3D model of the simulation model. The tests and controls shown in table 1 have been entered into the program as activities 1,2 , etc. with the sequence numbers specified in accordance with the simulation model after improvements (Figure 3).

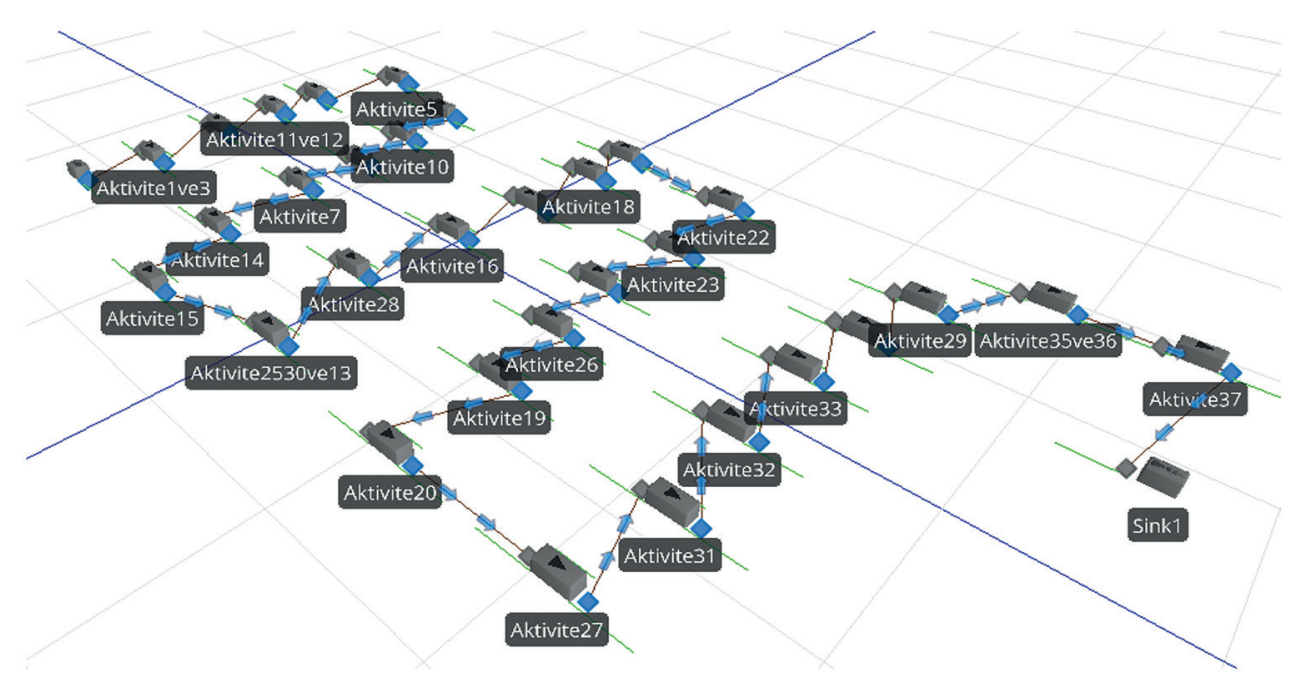

Figure 4. The Cruising Flow Diagram Provided from the Program 
Table 2. The Result of Current Status of Simulation Model

\begin{tabular}{|l|l|l|l|}
\hline \multicolumn{5}{|l|}{ Time In system-Average } & Data Source & Category & Value \\
\hline Object Name & [Population] & Flow Time & 28,0989 \\
\hline Ship & [Destroyed Entities] & Flow Time & 28,0989 \\
\hline Sink1 & Data Source & Category & Value \\
\hline Time In System-Maximum & Flow Time & 28,0989 \\
\hline Object Name & [Population] & Flow Time & 28,0989 \\
\hline Ship & [Destroyed Entities] & \multicolumn{1}{l|}{} \\
\hline Sink1 & Data Source & Category & Value \\
\hline Time In System-Minimum & [Population] & Flow Time & 28,0989 \\
\hline Object Name & [Destroyed Entities] & Flow Time & 28,0989 \\
\hline Ship & &
\end{tabular}

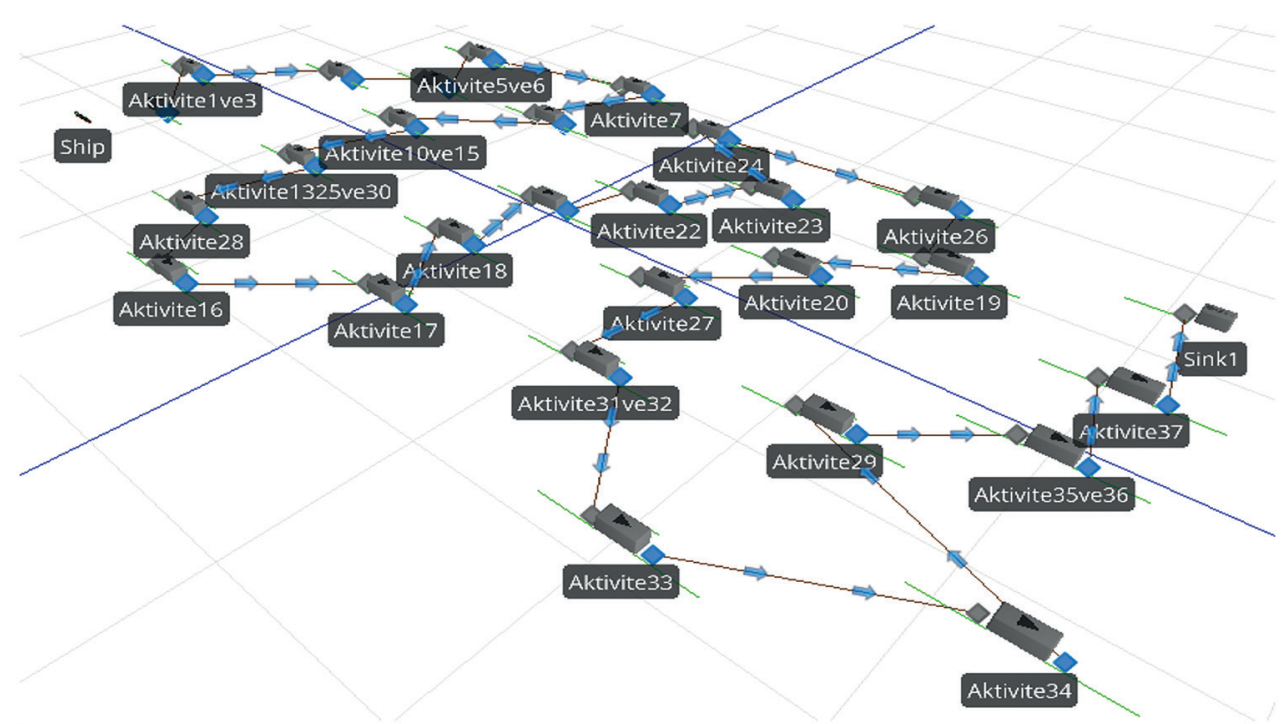

Figure 5. The Cruising Flow Diagram After the Improvement

After creating the new model in the program under normal conditions, the program has been run to find out how long the tests will be completed, and the total duration has been recorded as 25,3567 hours shortened by 2,75 hours for the new situation (Table 3). This amount of shortening corresponds to $9,76 \%$ of the total cruising time calculated before the improvement.

In the tests carried out on the program, it was accepted that there was no breakdown of the ship during the period from the beginning to the end of the tests and that the weather and sea conditions were suitable for cruising. 
Table 3. The Result of the New Status of Simulation Model

\begin{tabular}{|l|l|l|l|}
\hline Time In system-Average & Data Source & Category & Value \\
\hline Object Name & [Population] & Flow Time & 25,3567 \\
\hline Ship & [Destroyed Entities] & Flow Time & 25,3567 \\
\hline Sink1 & \multicolumn{4}{l|}{} \\
\hline Time In System-Maximum & Data Source & Category & Value \\
\hline Object Name & [Population] & Flow Time & 25,3567 \\
\hline Ship & [Destroyed Entities] & Flow Time & 25,3567 \\
\hline Sink1 & \multicolumn{5}{|l}{} \\
\hline Time In System-Minimum & Data Source & Category & Value \\
\hline Object Name & [Population] & Flow Time & 25,3567 \\
\hline Ship & [Destroyed Entities] & Flow Time & 25,3567 \\
\hline Sink1 &
\end{tabular}

Examples to the differences between the first cruising model and the second cruising model:

- Tests number 5 (boiler controls and alarms) and 6 (bow thruster STBS), which are planned to be carried out sequentially in the first cruising model, were determined as parallel tests in the second model with different personnel in the same time zone.

- Likewise, the tests number 10 (separator test and its alarms) and 15 (anchor windlass PS), which are planned to be carried out sequentially in the first cruising model, have been shown parallel in the second model.

- In addition, the sequence of the tests has been changed in general.

\section{Conclusions}

In this study, it is emphasized that the sea trial can be completed in a shorter time. For this purpose, the tests to be carried out in the cruise are shown in the form of items with their periods, and the periods of the tests to be entered into the SIMIO program have been determined in accordance with the triangular distribution.

The flow diagram of the test plan formed under normal conditions has been prepared and entered to the program. The program has been run afterwards, and it has been understood that the total time spent on the tests during the sea trial is 28,0989 hours. Then, the new flow diagram created as a consequence of the improvements made on the test plan has been entered to the program again. As a result of this process, it is seen that the total time spent on the tests is 25,3567 hours. As a result, when the flow chart is formed after the improvement is applied, the cruise is completed in less than 2.75 hours. In this case, the total spent time for the cruise tests decreased by a $9,76 \%$ ratio compared to the first case. Thus, it can be deduced that the test procedure in the second cruise flow diagram is more useful. What is important here is to ensure that the necessary arrangements in the tests are carried out in parallel (in the same process) with the cruise and that the personnel comply with the work plan. This will shorten the total time spent on tests.

In subsequent studies related to the sea trial, better results can be shown in terms of reducing the total spent time on the tests by designing different scenarios on the cruise flow diagrams formed for the tests. Similar 
simulation studies can also be conducted on military ships that have more sophisticated sea trial procedures than merchant ships. It is understood that it would be useful to use these and similar simulation programs effectively in the shipbuilding industry to be able to produce high quality ships in a shorter period and to improve the on-time delivery performance of shipyards.

\section{References}

[1] Fisher, K., W. (2003). Shipbuilding Contracts and Specifications, Chapter 9 of Ship Design and Construction. Society of Naval Architect and Marine Engineers, Jersey City, USA.

[2] Abdel-latif, S., Abdel-geliel, M. and Zakzouk, E., E. (2013). Simulation of Ship Maneuvering Behavior Based on the Modular Mathematical Model. 21st Mediterranean Conferance on Control \& Automation, June, Crete, Greece, 94-99.

[3] IMO Circular MSC/Circ. (2002). Explanatory Notes to the Standards for Ship Manoeuvrability. International Maritime Organization, 1053.

[4] Ponsignon, T. and Mönch, L. (2010). Architecture for Simulation-Based Performance Assement of Planning Approaches in Semiconductor Manufacturing. Winter Simulation Conference, December, Baltimore, MD, USA, 3341-3349.

[5] Medeiros, D., J., Traband, M., Tribble, A., Lepro, R., Fast, K. and Williams, D. (2000). Simulation Based Design for a Shipyard Manufacturing Process. Winter Simulation Conferance, December, Baltimore, MD, USA, 1411-1414.

[6] Caprace, J., D., Silva, C., T., D., Rigo, P. and Pires, F., C., M. (2011). Discrete Event Production Simülation and Optimisation of Ship Block Erection Process. 10th International Conference on Computer Applications and Information Technology in the Maritime Industries, May, Berlin, Germany, 271-282.
[7] Roh, M., I. and Lee, K., Y. (2007). Generation of Production Material Information for a Building Block and Simulation of Block Erection for Process Planning and Scheduling in Shipbuilding. International Journal of Production Research, 45(20), 4653-4683.

[8] Yuguang, Z. (2012). Optimization of Block Erection Scheduling Based on a Petri Net and Discrete PSO. International Journal of Production Research, 50(20), 5926-5935.

[9] Lamb, T.,Chung, H., Spicknall, N., Shin, J., G., Woo, J., H. and Koenig, P. (2006). Simulation-Based Performance Improvement for Shipbuilding Processes, Journal of Ship Production, 22(2), 49-65.

[10] Cheng, F. and Hongxiang, R. (2015). The Evaluating Simulation System of Ship Anchoring Operation. 34th Chinese Control Conference, July, Hangzhou, China, 8834-8837.

[11] Cha, J., H., Roh, M., I. and Lee, K., Y. (2010). Integrated Simulation Framework for the Process Planning of Ships and Offshore Structures. Robotics and Computer-Integrated Manufacturing, 26, 430-453.

[12] Nam, J., H., Lee, J., H. and Woo, J., H. (2016). Construction of Standardized Data Structure for Simulation of Shipbuilding Process. International Journal of Computer Integrated Manufacturing, 29(4), 424-437.

[13] Cha, J., H., Lee, K., Y., Ham, S., H., Roh, M., I., Park, K., P. and Suh, H., W. (2009). Discrete Event/Discrete Time Simulation of Block Erection by a Floating Crane Based on Multibody System Dynamics. International Offshore and Polar Engineering Conference, June, Osaka, Japan, 678685. 
[14] Shin, J., G. and Sohn, S., J. (2000). Simulation-Based Evaluation of Productivity for the Design of an Automated Fabrication Workshop in Shipbuilding. Journal of Ship Production, 16(1), 46-59.

[15] Ljubenkov, B., Dukic, G. and Kuzmanic, M. (2008). Simulation Methods in Shipbuilding Process Design. Journal of Mechanical Engineering, 54(2), 131139.

[16] Kim, H., Lee, S., S., Park, J., H. and Lee, J., G. (2005). A Model for Simulation-Based Shipbuilding System in a Shipyard Manufacturing Process, International Journal of Computer Integrated Manufacturing, 18(6), 427-441.

[17] Lee, K., Shin, J., G. and Ryu, C. (2009). Development of Simulation-Based Production Execution System in a Shipyard: a Case Study for a Panel Block Assembly Shop. Production Planning \& Control, 20(8), 750-768.

[18] Hadjina, M. (2009). Simulation Modelling Based Methodology for Shipbuilding Production Process Design. Journal for the Ory and Application in Mechanical Engineering, 51(6), 547-553.

[19] Vik, P., Dias, L., Pereira, G., Oliveira J. and Abreu, R. (2010). Using SIMIO for the Specification of an Integrated Automated Weighing Solution in a Cement Plant. Winter Simulation Conference, December, Baltimore, MD, USA, 1534-1543.

[20] Mandalaki, G. and Manesis, S. (2013). 3D Simulation Analysis of Patras New Port Operations in SIMIO Platform Environment. UK Sim 15th International Conference on Computer Modeling and Simulation, April, UK, 554-558.

[21] Ozkok, M. (2017). Investigation of Single Section Part Fabrication in Shipbuilding by Utilizing Simulation Environment. Journal of Science and Engineering, 19(55), 79-91.
[22] Jeong, Y., K., Lee, P. and Woo, J., H. (2018). Shipyard Block Logistics Simulation Using Process-Centric Discrete Event Simulation Method. Journal of Ship Production and Design, 34(2), 168-179.

[23] Du, J., W., Wang, J., J. and Fan, X., M. (2019). A simulation-based Dynamic Spatial Scheduling Method of Block Assembly in Shipbuilding. 2019 IEEE International Conference on Industrial Engineering and Engineering Management, December, Macao, 1491-1495.

[24] Lee, Y., G., Ju, S. and Woo, J., H. (2020). Simulation-based Planning System for Shipbuilding. International Journal of Computer Integrated Manufacturing, 33(6), 626-641.

[25] Ju, S., Sung, S., Shen, H., Jeong, Y., K. and Shin, J., G. (2020). System Development for Establishing Shipyard Mid-Term Production Plans Using Backward Process-Centric Simulation. International Journal of Naval Architecture and Ocean Engineering, 12(2020), 20-37. 